\title{
Signaling and Regulation of the Mitochondrial Unfolded Protein Response
}

\author{
Nandhitha Uma Naresh and Cole M. Haynes \\ Department of Molecular, Cell and Cancer Biology, University of Massachusetts Medical School, Worcester, \\ Massachusetts 01605 \\ Correspondence: cole.haynes@umassmed.edu
}

\begin{abstract}
The mitochondrial proteome encompasses more than a thousand proteins, which are encoded by the mitochondrial and nuclear genomes. Mitochondrial biogenesis and network health relies on maintenance of protein import pathways and the protein-folding environment. Cell-extrinsic or -intrinsic stressors that challenge mitochondrial proteostasis negatively affect organellar function. During conditions of stress, cells use impaired protein import as a sensor for mitochondrial dysfunction to activate a stress response called the mitochondrial unfolded protein response $\left(U P R^{\mathrm{mt}}\right)$. UPR ${ }^{\mathrm{mt}}$ activation leads to an adaptive transcriptional program that promotes mitochondrial recovery, metabolic adaptations, and innate immunity. In this review, we discuss the regulation of UPR ${ }^{\mathrm{mt}}$ activation as well as its role in maintaining mitochondrial homeostasis in physiological and pathological scenarios.
\end{abstract}

M itochondria are double-membrane-bound organelles of endosymbiotic origin (Gray 2012). Often, they are described as the "powerhouse of the cell" for their bioenergetic function of cellular ATP generation by oxidative phosphorylation (OXPHOS). In addition, mitochondria are required for innate immunity, maintaining calcium homeostasis, synthesis of numerous cofactors, including heme and ironsulfur clusters, as well as regulating apoptosis (Vandecasteele et al. 2001; Wang and Youle 2009; Stehling and Lill 2013; Weinberg et al. 2015). Mitochondria also act as platforms for metabolic pathways, including the TCA cycle, the urea cycle, $\beta$-oxidation, and lipid synthesis. The functional versatility and adaptability of the organelle depends on the concerted action by numerous proteins, protein complexes, and stress-response pathways.

Mitochondria are composed of more than 1000 proteins. Only 13 proteins are encoded by the mitochondrial genome (mitochondrial DNA [mtDNA]); all of which are components of the respiratory chain or ATP synthase (Anderson et al. 1981). All other mitochondrial proteins are encoded by nuclear genes, synthesized on cytosolic ribosomes, and subsequently imported into mitochondria via the TIM/TOM complexes (translocase of inner and outer membrane) (Chacinska et al. 2009). Given the high-protein concentration within mitochondria, coupled with complications deriving from the endosymbiotic origin of the organelle, maintenance of organellar protein homeostasis is

Editors: Richard I. Morimoto, F. Ulrich Hartl, and Jeffery W. Kelly

Additional Perspectives on Protein Homeostasis available at www.cshperspectives.org

Copyright (C) 2019 Cold Spring Harbor Laboratory Press; all rights reserved; doi: 10.1101/cshperspect.a033944

Cite this article as Cold Spring Harb Perspect Biol 2019;11:a033944 
challenging. Perturbations to proteostasis are caused by localized reactive oxygen species (ROS) production during normal and aberrant OXPHOS as well as uncoordinated expression of mitochondrial proteins encoded by either the mtDNA or nuclear genome (Curtis et al. 2012). Additionally, mutations in mtDNA and accumulation of damaged mtDNA adversely affect mitochondrial proteostasis (Moehle et al. 2018). Ultimately, such perturbations impair cellular health and are implicated in aging and several age-related diseases. For example, multiple studies have shown that mice harboring a mutation that annuls the proofreading activity of the mtDNA polymerase POLG $\gamma$ have increased mtDNA mutations concomitant with an accelerated aging phenotype (Trifunovic et al. 2004; Kujoth et al. 2005). Thus, understanding pathways in place to maintain mitochondrial proteostasis and function not only provide insights into disease etiology but may also lead to new therapeutic approaches.

\section{MITOCHONDRIAL BIOGENESIS, PROTEIN IMPORT, AND PROTEOSTASIS}

Mitochondrial biogenesis is an elaborate process involving membrane synthesis, mtDNA replication, as well as import and trafficking of those proteins synthesized in the cytosol to the appropriate intramitochondrial compartments (outer membrane, intermembrane space, inner membrane, or matrix). Here, we focus on the trafficking of proteins to the matrix, which typically requires a mitochondrial targeting sequence (MTS) on the amino terminus of the protein to be imported. The MTS is a positively charged, amphipathic $\sim 25-35$ amino acid sequence that first interacts with the TOM complex before import (Mayer et al. 1995; Meisinger et al. 2001; Saitoh et al. 2007). On passing through the TOM complex in an unfolded state, precursor proteins translocate through the TIM23 complex, which requires the inner membrane potential generated by a functional respiratory chain (Martin et al. 1991). Finally, preproteins translocate into the mitochondrial matrix, which also requires the matrix-localized molecular chaperone mtHsp70 (Mapa et al. 2010). mtHsp70 interacts directly with the TIM23 complex via cochaperones and facilitates import by either actively pulling proteins into the matrix or passively trapping preproteins to prevent retrograde diffusion out of the matrix (Gaume et al. 1998; Voisine et al. 1999; D'Silva et al. 2003). Once in the matrix, MTS is cleaved by the mitochondrial processing peptidase (MPP). Thus, mtHsp70 plays a dual role during protein import, both at the import channel and in the matrix to assist in proper protein handling. In yeast, it has been shown that the distinct functional roles of $\mathrm{mtHsp} 70$ in protein import and protein folding in the matrix can be attributed to its differential interactions with cochaperones forming two different complexes (Horst et al. 1997). At the import complex, mtHsp70 associates with Tim44 of the TIM23 complex, whereas in the matrix it interacts with Mdj1, the DnaJ homolog (Horst et al. 1997).

Chaperone-assisted protein folding following import is key to maintaining proteostasis in the matrix. In addition to mtHsp70, the chaperonin Hsp60 also interacts with imported proteins in the matrix to facilitate protein folding (Cheng et al. 1989). Hsp60s in cooperation with Hsp10 undergoes ATP-dependent conformational changes to form a protective socket that allows substrate proteins to fold within them by preventing contact with other surrounding proteins. Hsp60 also plays a protective role under conditions of heat stress by preventing aggregate formation (Bender et al. 2011).

Moreover, mitochondrial-localized qualitycontrol proteases maintain proteostasis by degrading damaged or terminally misfolded proteins. The AAA proteases LON and ClpXP are largely responsible for removing damaged proteins from the mitochondrial matrix (Tatsuta and Langer 2009). Also, paraplegin and YMEL1 primarily prevent misfolding of respiratory chain complex proteins on or near the mitochondrial inner membrane (Leonhard et al. 1996).

In addition to OXPHOS activity and mitochondrial proteostasis, numerous additional factors in multiple cellular compartments contribute to the regulation and efficiency of mitochondrial protein import. For example, 
Regulation of the Mitochondrial Unfolded Protein Response

phosphorylation of an MTS can reduce import efficiency (Colombo et al. 2005; Boopathi et al. 2008; Rao et al. 2011). In the cytosol, protein import can be regulated by the binding of protein partners or metabolites to precursor proteins (Vongsamphanh et al. 2001; Munakata et al. 2004). For instance, import of the mitochondrial protein 5-aminolevulinate is impaired on heme binding in the cytosol (Dailey et al. 2005). Folding of the precursor proteins before interacting with the TOM channel can inhibit entry (Hill et al. 1998; Truscott et al. 2001; Strobel et al. 2002). As the majority of protein import requires the TOM complex, mechanisms that modulate the activity of the import machinery influence the entry of precursor proteins (Harbauer et al. 2014). Studies in yeast have shown that casein kinases (CKs) and protein kinase A (PKA) can phosphorylate TOM to modulate protein import. CKs phosphorylate Tom 22 to promote import, whereas PKA phosphorylates Tom40, Tom22, as well as Tom70 to impair protein import (Schmidt et al. 2011; Rao et al. 2012; Gerbeth et al. 2013).

Mitochondrial function and proteostasis are integrally linked with mitochondrial protein import. For example, mitochondrial uncoupling or dissipation of the inner membrane potential because of OXPHOS defects directly inhibits protein translocation into the mitochondria. Furthermore, proteostasis perturbations require mtHsp70 to facilitate protein folding, which may impact the chaperones' role in mitochondrial protein import. Because protein import capacity and proteostasis correlate with mitochondrial function, import efficiency can serve as a sensor for detecting perturbations in mitochondrial homeostasis. At least two mitochondrial stress responses are regulated by mitochondrial import capacity. Severe impairment of protein import leads to degradation of the entire compartment via mitochondrial autophagy (mitophagy) (Pickles et al. 2018). Impaired import also leads to activation of an adaptive transcriptional response known as the mitochondrial unfolded protein response $\left(\mathrm{UPR}^{\mathrm{mt}}\right)$, which promotes recovery of mitochondrial function (Shpilka and Haynes 2018). In this review, we focus on the mechanisms that regulate $U P R^{\mathrm{mt}}$ activation and its role in diverse physiological scenarios.

\section{UPR $^{\mathrm{mt}}$ REGULATION}

The UPR ${ }^{\mathrm{mt}}$ was initially discovered in cultured mammalian cells in which depletion of mtDNA or overexpression of a mitochondrial-targeted protein harboring a deletion rendering the protein terminally misfolded $(\triangle \mathrm{OTC})$ elicited a transcriptional response that included mitochondrial molecular chaperones and qualitycontrol proteases (Martinus et al. 1996; Zhao et al. 2002). Over the ensuing years, findings in Caenorhabditis elegans have identified components in multiple subcellular compartments providing insight into how cells detect mitochondrial dysfunction and communicate with the nucleus to adapt transcription accordingly. Importantly, homologous $\mathrm{UPR}^{\mathrm{mt}}$ regulatory components have been identified in mammalian systems, demonstrating the evolutionary conservation of the adaptive mitochondrial stress response (Fiorese et al. 2016; Münch and Harper 2016; Quirós et al. 2017).

\section{Stressors that Perturb Mitochondria and Activate the UPR ${ }^{\mathrm{mt}}$}

A diverse number of stressors, which impair mitochondrial function, activate the UPR ${ }^{\mathrm{mt}}$. Stressors that perturb mitochondrial proteostasis components, such as molecular chaperones and quality-control proteases, are among the strongest inducers of the UPR ${ }^{\mathrm{mt}}$, possibly owing to the accumulation of misfolded proteins in the mitochondria, which exceeds the proteinhandling capacity of chaperones and proteases, thereby hindering protein import (Yoneda et al. 2004). Consistent with this model, inhibiting import directly by depleting the import complex TIM (timm-23) strongly activates the UPR ${ }^{\mathrm{mt}}$ (Nargund et al. 2012). Furthermore, inhibition of mitochondrial protein synthesis via RNA interference (RNAi) or mitochondrial ribosome inhibitors, such as doxycycline or chloramphenicol, activates the UPR ${ }^{\mathrm{mt}}$ (Yoneda et al. 2004; Houtkooper et al. 2013). 
In addition to perturbations in proteostasis, impairment of mitochondrial metabolic functions also elicits $\mathrm{UPR}^{\mathrm{mt}}$ activation. For example, mtDNA depletion by treatment with ethidium bromide activates the UPR ${ }^{\mathrm{mt}}$ (Yoneda et al. 2004; Houtkooper et al. 2013). Inhibition of OXPHOS by multiple compounds, including rotenone (complex I inhibitor), antimycin (complex III inhibitor), oligomycin (complex V inhibitor), or paraquat, also activates the UPR ${ }^{\mathrm{mt}}$ (Yoneda et al. 2004; Runkel et al. 2013). Lastly, inhibition of fumarate hydratase, the enzyme responsible for converting fumarate to malate in the TCA cycle, activates the UPR ${ }^{\mathrm{mt}}$, indicating that the mitochondrial stress response is engaged by both mitochondrial proteostasis and metabolic perturbations (Wang et al. 2016b).

\section{Transcriptional Program Mediated} by $\mathrm{UPR}^{\mathrm{mt}}$ Activation

\section{Mitochondrial Network Recovery and Function}

The mitochondrial recovery program elicited by $\mathrm{UPR}^{\mathrm{mt}}$ activation includes induction of mitochondrial chaperones Hsp60 and mtHsp70, which promote protein folding and prevent aggregate formation. To eliminate the accumulation of damaged or misfolded proteins, the ATPdependent m-AAA and i-AAA proteases, such as paraplegin and YMEL-1, are induced as are superoxide dismutases (SODs) to limit the accumulation of ROS from dysfunctional OXPHOS.

In addition to a transcriptional response induced for repair and recovery of damaged mitochondria, the UPR ${ }^{\mathrm{mt}}$ activation also induces genes that promote mitochondrial biogenesis and function, including iron-sulfur cluster and ubiquinone synthesis required for OXPHOS complex biogenesis. UPR ${ }^{\mathrm{mt}}$ activation also induces genes involved in mitochondrial fission, such as Dynamin-related protein (Drp1), to promote mitochondrial biogenesis as well as clearance of defective mitochondria.

\section{Metabolic Adaptations}

Most OXPHOS components are encoded by nuclear genes and assembled into complexes via chaperones and assembly factors. UPR ${ }^{\mathrm{mt}}$ activation limits the transcription of OXPHOS components possibly to reduce the load on the proteostasis machinery during stress (Nargund et al. 2015). Concomitantly, UPR ${ }^{\mathrm{mt}}$ activation induces all glycolysis genes, suggesting that $\mathrm{UPR}^{\mathrm{mt}}$ plays a role in balancing the metabolic landscape of the cell during mitochondrial stress likely by promoting an alternative means of ATP synthesis to facilitate mitochondrial recovery.

\section{Mitochondria-to-Nuclear Communication}

Genetic screens in C. elegans have revealed multiple components required for $\mathrm{UPR}^{\mathrm{mt}}$ activation, including the bZIP transcription factor associated with Stress-1 (ATFS-1) (Fig. 1). In addition to its bZIP DNA-binding domain, ATFS-1 also harbors both an MTS and a nuclear localization sequence (NLS) (Nargund et al. 2012). The net positive charge of the MTS facilitates its import into functional mitochondria, in which the MTS is cleaved and the remainder of the protein is degraded by the matrix-localized protease LONP1. However, during mitochondrial stress, a decline in mitochondrial function reduces import efficiency of ATFS-1 causing a fraction of the transcription factor to remain in the cytosol. Because ATFS-1 harbors an NLS, it then traffics to the nucleus to initiate a transcriptional program (Nargund et al. 2012). Thus, mitochondrial import efficiency of ATFS-1 allows cells to sense and monitor perturbations in mitochondrial network health and homeostasis (Haynes et al. 2010). In line with this model, mutations that reduce the strength of ATFS-1's MTS limit its mitochondrial import efficiency and constitutively activate the $\mathrm{UPR}^{\mathrm{mt}}$ (Rauthan et al. 2013).

ATFS-1 is activated by impaired mitochondrial protein import. But, how are the induced proteostasis components, such as chaperones and proteases, imported into mitochondria to facilitate recovery? One possibility is that ATFS1 activation transcriptionally induces genes encoding the import machinery, thereby gradually increasing mitochondrial protein import as well as protein-handling capacity. Another possibility is that because mitochondrial chaper- 


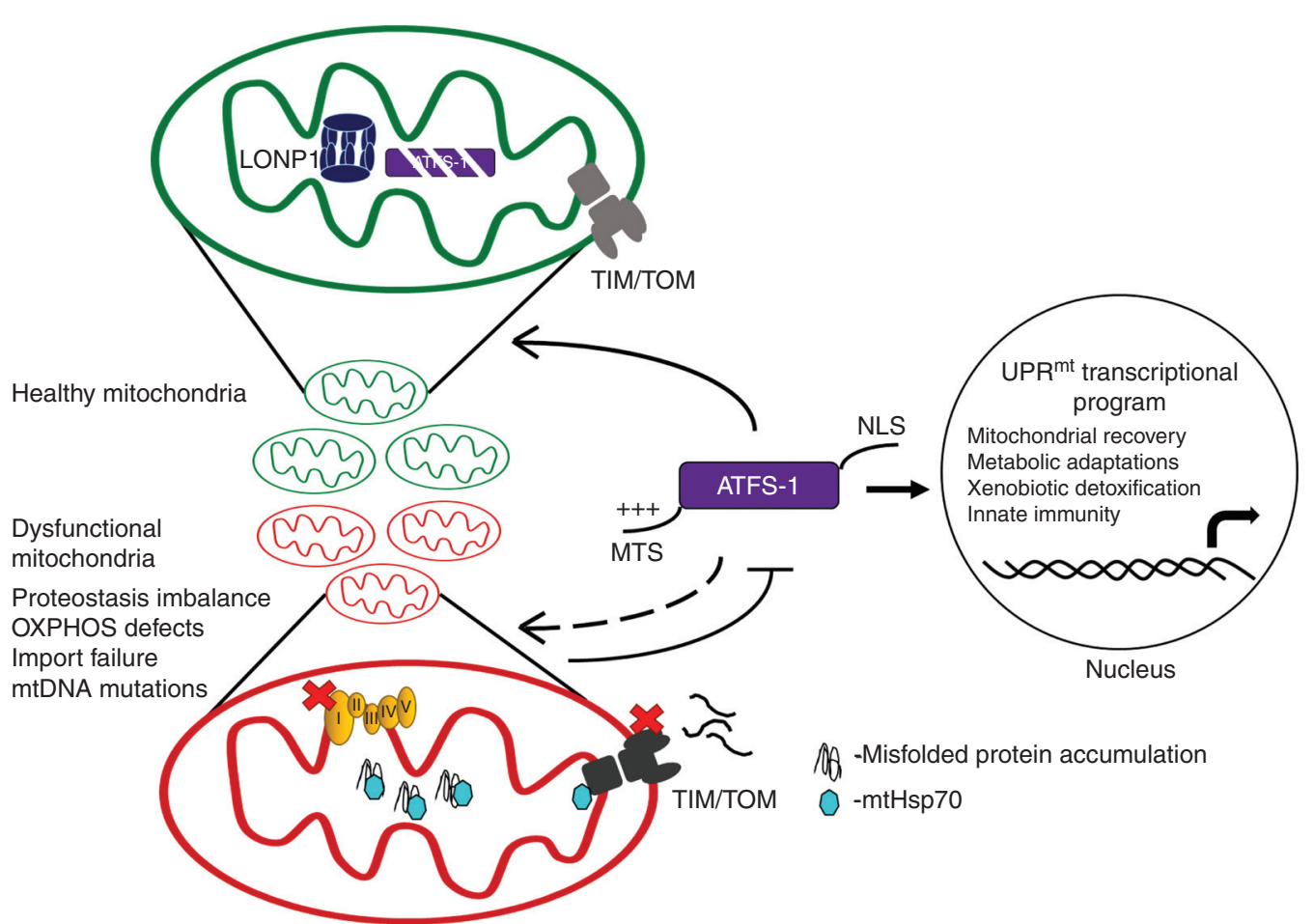

Figure 1. Regulation of the mitochondrial unfolded protein response (UPR ${ }^{\mathrm{mt}}$ ) by ATFS-1. UPR ${ }^{\mathrm{mt}}$ activation is mediated by the transcription factor ATFS-1, which harbors a mitochondrial targeting sequence (MTS) as well as a nuclear localization sequence (NLS). When mitochondria are healthy, ATFS-1 is imported via the TIM/TOM (translocase of the inner and outer membrane) complex and subsequently degraded by the matrix-localized protease LONP1. Mitochondrial import of most precursor proteins and efficient folding within the matrix requires the matrix-localized chaperone $\mathrm{mtHsp70} \mathrm{located} \mathrm{at} \mathrm{both} \mathrm{the} \mathrm{import} \mathrm{channel} \mathrm{as} \mathrm{well} \mathrm{as} \mathrm{in} \mathrm{the} \mathrm{matrix.}$ Mitochondrial dysfunction because of impaired proteostasis or oxidative phosphorylation (OXPHOS) reduces mitochondrial protein import efficiency of ATFS-1, allowing it to traffic to the nucleus to initiate a transcriptional program, which promotes the recovery of mitochondrial function.

ones, such as mtHsp70, play a dual role at the import complex and in the matrix for protein folding, reduced import capacity during stress may be concomitant with spatial redistribution of $\mathrm{mtHsp70}$ and other chaperones from the sites of protein import to the sites of accumulated or misfolded proteins. Alternatively, ATFS-1 may simply have a relatively weak MTS, and the proteins induced by ATFS- 1 may have strong MTSs, enabling them to be imported into dysfunctional mitochondria (Melber and Haynes 2018).

In addition to ATFS-1, several other proteins required for $\mathrm{UPR}^{\mathrm{mt}}$ activation have been identified. The homeobox domain transcription factor DVE-1 forms a complex with the ubiqui- tin-like protein UBL-5, and remodels chromatin by binding to $\mathrm{UPR}^{\mathrm{mt}}$ gene promoters such as hsp-60 (Benedetti et al. 2006; Haynes et al. 2007; Tian et al. 2016). Presumably, chromatin remodeling enables ATFS- 1 to bind the UPR ${ }^{\mathrm{mt}}$ element in the promoters of UPR ${ }^{\mathrm{mt}}$ genes (Nargund et al. 2015).

The Role of Chromatin Remodeling in $\mathrm{UPR}^{\mathrm{mt}}$ Activation

Epigenetic regulation by chromatin remodeling plays an important role in $\mathrm{UPR}^{\mathrm{mt}}$ activation during mitochondrial dysfunction. A recent study has shown that mitochondrial stress caused by knockdown of prohibitin or a respi- 
ratory chain complex IV subunit leads to nuclear localization of the chromatin modifier LIN65 (Tian et al. 2016). LIN-65 function requires the H3K9 methyltransferase MET-2. Combined, these factors reorganize global chromatin structure and alter compaction to enable transcription of $\mathrm{UPR}^{\mathrm{mt}}$ genes in response to stress (Tian et al. 2016).

The histone demethylases jmjd-1.2 and jmjd-3.1, members of the H3K27 family containing jmC-domain, are also necessary to activate the $\mathrm{UPR}^{\mathrm{mt}}$ when OXPHOS is impaired (Merkwirth et al. 2016). Furthermore, jmjd-1.2 and jmjd-3.1 overexpression is sufficient to induce the UPR ${ }^{\mathrm{mt}}$ and increase longevity. Both demethylases remove repressive chromatin marks and, therefore, positively regulate gene expression by promoting access of the transcriptional machinery to $\mathrm{UPR}^{\mathrm{mt}}$ gene promoters. The mechanisms that stimulate the activity of JMJD1.2 and JMJD-3.1 during mitochondrial stress are unclear, but may relate to the regulation of these demethylases by metabolic cofactors, including $\alpha$-ketoglutarate (a TCA-cycle intermediate) and iron (Tsukada et al. 2006). Production of such metabolic cofactors largely depends on healthy mitochondrial function and ATP generation (Teperino et al. 2010). During mitochondrial dysfunction, changes in metabolic pathways may alter the level of these metabolites, consequently affecting the activity of histone demethylases to promote $\mathrm{UPR}^{\mathrm{mt}}$ activation.

\section{$\mathrm{UPR}^{\mathrm{mt}}$ Regulation and the Integrated Stress Response}

Transcriptional regulation of the $\mathrm{UPR}^{\mathrm{mt}}$ in mammalian cells is comparable to that in $C$. elegans and is mediated by multiple bZIP transcription factors including ATF5 (Fiorese et al. 2016). Much like ATFS-1, ATF5 harbors an MTS and is regulated by organelle partitioning. Importantly, ATF5 rescues $\mathrm{UPR}^{\mathrm{mt}}$ activation in nematodes lacking ATFS-1 and cultured cells, ATF5 transcriptionally up-regulates mitochondrial chaperones and proteases during mitochondrial stress (Fiorese et al. 2016).

However, in mammalian systems, UPR ${ }^{\mathrm{mt}}$ activation requires at least two additional bZIP proteins, ATF4 and CHOP, as rotenone exposure transcriptionally up-regulates both ATF4 and CHOP (Horibe and Hoogenraad 2007; Silva et al. 2009; Quirós et al. 2017). Furthermore, mtDNA depletion causes induction of ATF4 and ATF5. All three transcription factors are linked to the integrated stress response (ISR), which is a conserved adaptive response activated by a wide variety of stressors. The ISR was first characterized in yeast as the "general control pathway," which is activated during amino acid deprivation. The yeast pathway was later found to be a highly conserved stress-response mechanism in mammalian systems (Harding et al. 2000). ISR initiation is mediated by kinases that respond to specific stressors and phosphorylate serine 51 of the translation initiation factor subunit eIF2 $\alpha$ (Pathak et al. 1988). The mammalian ISR kinases are RNA-dependent protein kinase (PKR)-like ER kinase (PERK), heme-regulated eIF $2 \alpha$ kinase (HRI), doublestranded $\mathrm{PKR}$, and general control nonderepressible 2 (GCN2). PERK, HRI, and PKR are specifically activated in response to perturbations in ER homeostasis, heme availability, and the presence of cytosolic double-stranded RNA, respectively (Meurs et al. 1990; Chen and London 1995; Harding et al. 1999). GCN2 is activated by amino acid or glucose deprivation, ROS, ribosome stalling, mitochondrial dysfunction, and UV light (Dever et al. 1992; Deng et al. 2002; Baker et al. 2012). Ultimately, eIF $2 \alpha$ phosphorylation causes attenuation of global protein synthesis while promoting the selective translation of messenger RNAs (mRNAs) harboring upstream open reading frames (uORFs) in the $5^{\prime}$ untranslated region ( $5^{\prime} \mathrm{UTR}$ ). The bZIP transcription factors CHOP, ATF4, and ATF5 are among the mRNAs selectively translated on eIF2 $\alpha$ phosphorylation.

In sum, ISR activation in mammals during stress causes eIF $2 \alpha$ phosphorylation, which promotes activation of the transcription factors ATF4, CHOP, and ATF5. However, the nuances of the interrelationship between the transcription factors during mitochondrial stress or which kinases are specifically activated by which mitochondrial perturbations is not yet fully understood. 
Regulation of the Mitochondrial Unfolded Protein Response

$\mathrm{UPR}^{\mathrm{mt}}$ and Translation Regulation within Mitochondria

mtDNA-encoded transfer RNAs (tRNAs) are essential for translation and RNA maturation within mitochondria. Following transcription, mitochondrial tRNAs are processed at the $5^{\prime}$ and $3^{\prime}$ ends by the RNase P and RNase Z complexes (Rossmanith 2012). In humans, RNase $\mathrm{P}$ is comprised of the proteins MRPP1, MRPP2, and MRPP3. During mitochondrial stress, $\mathrm{UPR}^{\mathrm{mt}}$ activation results in decreased MRPP3 caused by increased degradation by LON protease (Münch and Harper 2016). Therefore, UPR ${ }^{\mathrm{mt}}$ activation reduces protein synthesis within the cytosol by phosphorylating eIF $2 \alpha$ and mitochondria by degradation of MRPP3 likely facilitating proteostasis and organelle recovery.

\section{Cell-Nonautonomous UPR ${ }^{\mathrm{mt}}$ Regulation}

In addition to mitochondrial-to-nuclear communication within each cell, mitochondrial dysfunction can be communicated between tissues to induce the $\mathrm{UPR}^{\mathrm{mt}}$. Recent studies in C. ele- gans and mammals indicate that intercellular communication involves secretion of signaling factors, called mitokines, from neurons with dysfunctional mitochondria. The mitokine(s) then act on peripheral cells, such as the intestinal cells, to activate the UPR ${ }^{\mathrm{mt}}$ (Fig. 2) (Durieux et al. 2011; Kim et al. 2013b; Berendzen et al. 2016; Shao et al. 2016). For example, FLP-2, a neuropeptide secreted from interneurons, acts as a signaling factor to activate the $U P R^{\mathrm{mt}}$ in intestinal cells when mitochondrial stress is induced specifically in neurons (Shao et al. 2016). A separate study showed that during neuronal proteotoxic stress, secretion of the neurotransmitter serotonin is also required for communication with intestinal cells to activate the UPR ${ }^{\mathrm{mt}}$ (Berendzen et al. 2016). In addition to FLP-2 and serotonin, Wnt signaling pathway is required for cell-nonautonomous UPR ${ }^{\mathrm{mt}}$ activation. Mitochondrial stress induced in neurons leads to secretion of the Wnt ligand EGL-20, which acts as a mitokine to induce the UPR ${ }^{\mathrm{mt}}$ in peripheral cells (Zhang et al. 2018).

In mammalian systems, the potential mitokine fibroblast growth factor 21 (FGF21), a met-

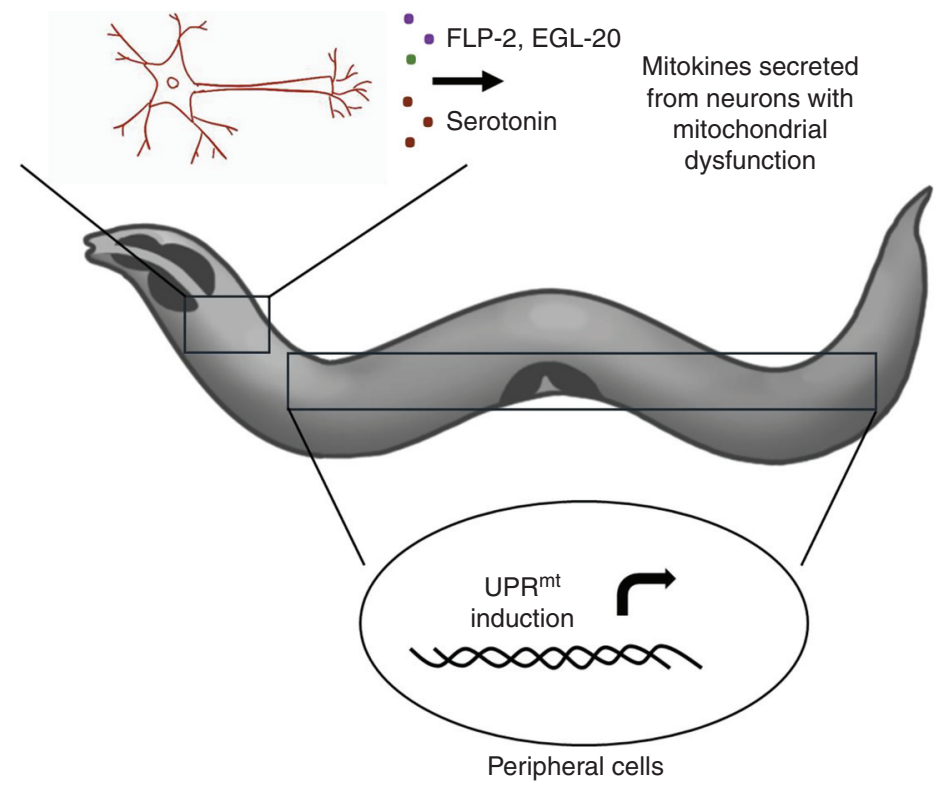

Figure 2. Cell-nonautonomous mitochondrial unfolded protein response (UPR $\left.{ }^{\mathrm{mt}}\right)$ signaling. Neuronal activation of the $\mathrm{UPR}^{\mathrm{mt}}$ is communicated cell nonautonomously to the intestine by the secretion of mitokines (FLP-2, serotonin, EGL-20) to activate the $\mathrm{UPR}^{\mathrm{mt}}$ in distal tissues such as the intestine. 
N. Uma Naresh and C.M. Haynes

abolic hormone expressed in multiple mammalian tissues, is induced by the ISR regulator ATF4 during mitochondrial stress caused by autophagy deficiency (Kim et al. 2013a,b). Growth differentiation factor 15 (GDF15) is also a potential mitokine, which is induced during mitochondrial stress in skeletal muscles (Chung et al. 2017). In mice, GDF15 induction causes changes in lipid metabolism and insulin sensitivity, thereby conferring tolerance to onset of obesity (Chung et al. 2017).

Physiologies and Pathologies Impacted by UPR ${ }^{\mathrm{mt}}$ Signaling

\section{UPR ${ }^{m t}$ Signaling and Organismal Longevity}

Decline in mitochondrial function is a hallmark of aging in most organisms and associated with accumulation of mtDNA mutations as well as reduced OXPHOS (Bratic and Larsson 2013). Surprisingly, considerable evidence indicates that modest mitochondrial perturbations cause increased longevity (Feng et al. 2001; Dillin et al. 2002; Liu et al. 2005; Copeland et al. 2009). In C. elegans, impairment of respiratory chain complex IV function (cco-1 RNAi) both activates the $\mathrm{UPR}^{\mathrm{mt}}$ and extends life span by $\sim 50 \%$ (Fig. 3) (Durieux et al. 2011). Interestingly, the life-span modulation is dependent on the developmental stage during which mitochondrial function is impaired, that is, increased longevity occurs only when $c c 0-1$ RNAi is administered before adulthood. This suggests that temporal regulation of mitochondrial function is associated with longevity, possibly owing to epigenetic level changes during different stages of development (Dillin et al. 2002; Durieux et al.

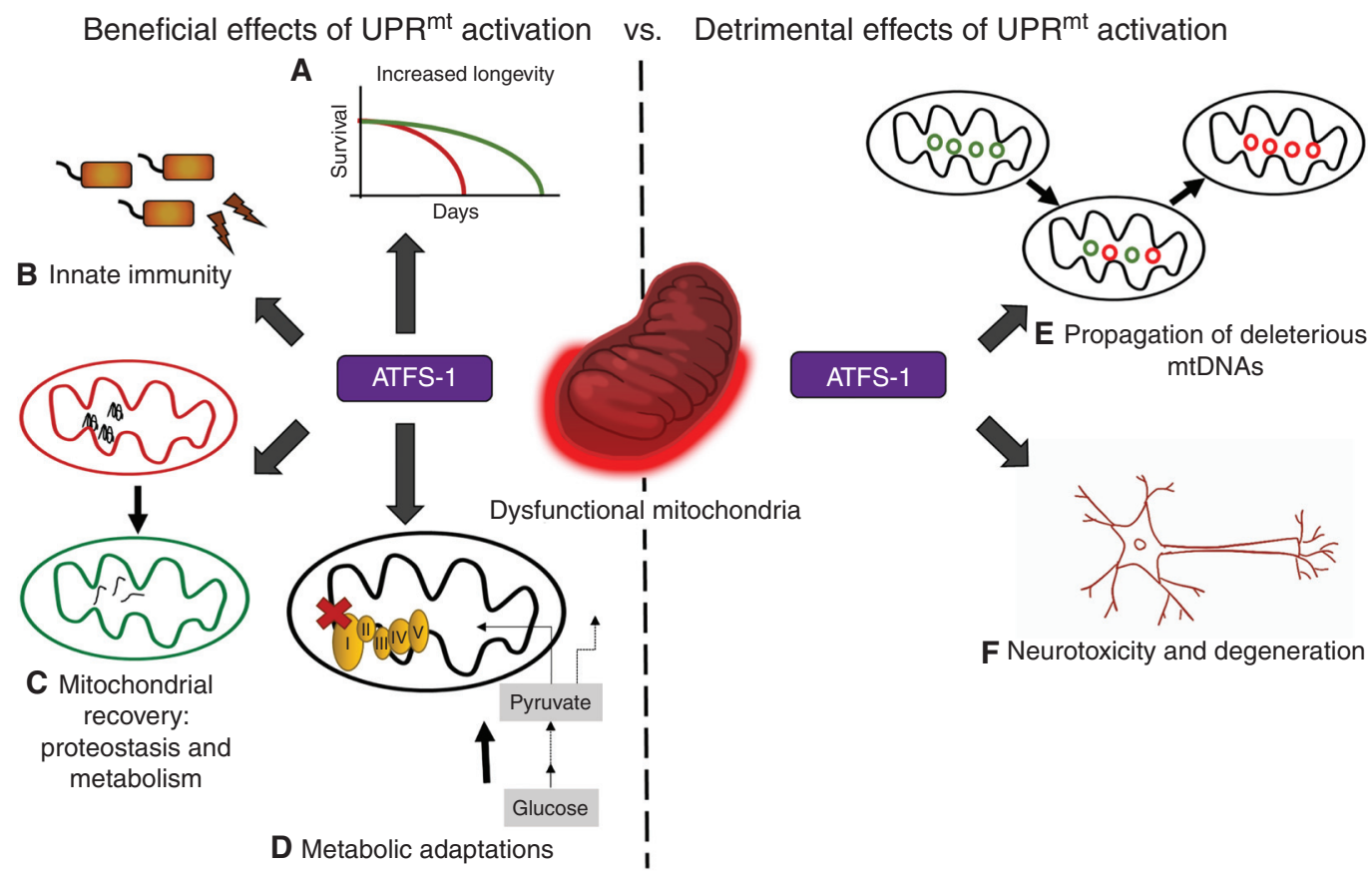

Figure 3. Functions and consequences of mitochondrial unfolded protein response (UPR $\left.{ }^{\mathrm{mt}}\right)$ activation. $U P R^{\mathrm{mt}}$ activation has beneficial, as well as detrimental effects, depending on the physiological scenario as well as duration and strength of activation. Beneficial outcomes include $(A)$ increased longevity, $(B)$ increased resistance against pathogen infection, $(C)$ efficient recovery of the mitochondrial network, and $(D)$ metabolic adaptations, including the induction of glycolysis. However, prolonged $U_{P R}{ }^{\mathrm{mt}}$ activation can result in $(E)$ amplification of deleterious mitochondrial DNAs (mtDNAs), and $(F)$ neurotoxicity, emphasizing the importance of proper $\mathrm{UPR}^{\mathrm{mt}}$ regulation. ATFS-1, Activated transcription factor associated with Stress-1. 
Regulation of the Mitochondrial Unfolded Protein Response

2011). Consistent with the role of mitochondria as central regulators of metabolic homeostasis, changes in metabolic inputs affecting mitochondrial function influence UPR ${ }^{\mathrm{mt}}$ activation and, in turn, impact life span. For example, modulating levels of the metabolic cofactor $\mathrm{NAD}^{+}$ activates the $\mathrm{UPR}^{\mathrm{mt}}$ and extends life span (Mouchiroud et al. 2013).

Parallel studies in multiple organisms have shown that modest mitochondrial perturbations, which cause UPR ${ }^{\mathrm{mt}}$ activation, also extend life span. A study in flies showed that inducing mitochondrial stress in muscle cells by perturbing respiratory chain function activates the $\mathrm{UPR}^{\mathrm{mt}}$, specifically in muscles, and promotes longevity (Owusu-Ansah et al. 2013). In mice, impaired function of mitochondrial ribosomes by genetic or pharmacological means both activates the UPR ${ }^{\mathrm{mt}}$ and extends life span (Houtkooper et al. 2013). Although considerable data indicate a role for the $\mathrm{UPR}^{\mathrm{mt}}$ in extending life span, the cellular processes impacted by UPR ${ }^{\mathrm{mt}}$ activation, which influence life span, remain to be identified.

\section{$U P R^{m t}$ Signaling in Propagation of Deleterious Mitochondrial Genome}

Most cells harbor hundreds of copies of the mitochondrial genome distributed among the mitochondrial network, which are inherited via the maternal germline (Miller et al. 2003). As mtDNA harbors 13 protein-coding genes that are all essential for OXPHOS, mtDNA mutations can cause a wide range of pathologies, including neuropathies and myoclonic epilepsy (Tuppen et al. 2010). mtDNA acquires mutations at a higher rate than the nuclear genome, possibly because of the lack of efficient DNA repair pathways or the presence of a mutagenic environment. Given the high copy number of mtDNA, such mutations are generally well tolerated as they coexist with wild-type mtDNAs in a state known as heteroplasmy. However, as cells such as muscle and neurons age, the deleterious mtDNA ( $\triangle \mathrm{mtDNA})$ often accumulates faster than the wild-type mtDNA, resulting in loss of OXPHOS. Although the mechanisms that underlie the preferential accumulation of
$\Delta$ mtDNAs remain largely unknown, recent work in two heteroplasmic C. elegans strains indicates a requirement for ATFS-1 and the $\mathrm{UPR}^{\mathrm{mt}}$ in maintaining the $\triangle \mathrm{mtDNA}$ (Gitschlag et al. 2016; Lin et al. 2016).

One such strain harbors $\sim 60 \% \Delta \mathrm{mtDNA}$ and $40 \%$ wild-type mtDNA. The $\triangle \mathrm{mtDNA}$ harbors a 3.1-kb deletion lacking four essential OXPHOS genes and perpetually activates the $\mathrm{UPR}^{\mathrm{mt}}$ as a result of reduced OXPHOS. Impressively, deletion of the atfs-1 gene results in nearly a complete loss of the $\Delta \mathrm{mtDNA}$, while having no effect on the wild-type genomes. Alternatively, hyperactivation of the UPR ${ }^{\mathrm{mt}}$ causes a preferential accumulation of the $\triangle \mathrm{mtDNA}$, indicating that $\mathrm{UPR}^{\mathrm{mt}}$ activation is both necessary and sufficient for the preferential accumulation of $\Delta$ mtDNAs (Fig. 3; Gitschlag et al. 2016; Lin et al. 2016). Although the outputs of $\mathrm{UPR}^{\mathrm{mt}}$ activation that promote $\Delta \mathrm{mtDNA}$ propagation remain unclear, evidence suggests that imbalanced mitochondrial biogenesis and mitophagy are involved in the process (Lin et al. 2016).

\section{$U P R^{m t}$ Signaling in Mitochondrial Diseases}

Dysfunctional mitochondria are manifested in several diseases that are currently incurable (Suomalainen 2015). An example of this is mitochondrial myopathy, a progressive disease associated with defective respiratory chain function and muscular abnormalities often resulting from accumulating mtDNA mutations (Pfeffer and Chinnery 2013). A recent study showed the link between mTORC1 (mechanistic target of rapamycin complex 1 ) and $\mathrm{UPR}^{\mathrm{mt}}$ regulation in a manner dependent on uORFs during mitochondrial myopathy. mTORC1 is a regulatory kinase that responds to nutrient availability, ATP production, and regulates protein synthesis through downstream effectors such as S6 kinase (Rohde et al. 2001; Magnuson et al. 2012). Using a mouse model of adult-onset mitochondrial myopathy caused by accumulating mtDNA deletions, the study showed that mitochondrial dysfunction stimulates mTORC1 (Khan et al. 2017). Interestingly, mTORC1 activation was required for induction of a transcriptional program, including cytokines such as FGF21 and 
GDF15, consistent with the UPR ${ }^{\mathrm{mt}}$. Importantly, mTORC1 activation caused transcriptional up-regulation of ATF4 and ATF5, which is impaired by treatment with the known mTORC1 inhibitor rapamycin (Khan et al. 2017). However, the mechanistic details of mTORC1-mediated translational regulation of ATF4 and ATF5 remains elusive (Khan et al. 2017).

\section{$U P R^{m t}$ Signaling in Neurodegenerative}

Diseases

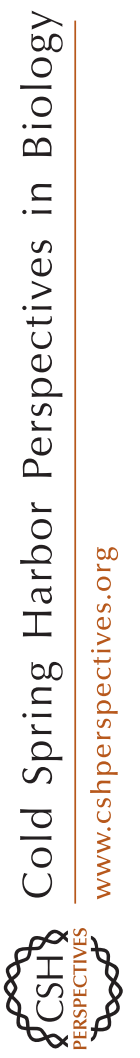

Alzheimer's disease, a progressive neurodegenerative condition associated with aging, is characterized by mitochondrial dysfunction along with proteotoxic aggregation of amyloid- $\beta(A \beta)$ peptides (Hashimoto et al. 2003). Recent work has suggested that the $\mathrm{UPR}^{\mathrm{mt}}$ is activated in neurons of Alzheimer's disease patients (Sorrentino 2017). Consistent with this data, expression of $\mathrm{A} \beta$ in $C$. elegans results in $\mathrm{UPR}^{\mathrm{mt}}$ activation (Sorrentino 2017). Impressively, enhanced $\mathrm{UPR}^{\mathrm{mt}}$ activation reduces the toxicity associated with $A \beta$ accumulation and prolongs survival. In mouse models of Alzheimer's disease treatment with nicotinamide riboside (NR), which boosts $\mathrm{NAD}^{+}$levels and activates the $\mathrm{UPR}^{\mathrm{mt}}$, alleviates proteoxicity, as well as improves memory (Sorrentino 2017). In brief, these findings suggest that strategies to enhance $\mathrm{UPR}^{\mathrm{mt}}$ activation may be useful in the treatment of Alzheimer's disease.

In contrast to the findings relating to $\mathrm{Alz}$ heimer's disease and the UPR ${ }^{\mathrm{mt}}$, prolonged or hyperactivation of the UPR ${ }^{\mathrm{mt}}$ causes dopaminergic neuron death in a $C$. elegans model of Parkinson's disease in which the protein $\alpha$-synuclein is overexpressed (Fig. 3) (Martinez et al. 2017). Combined, these results indicate that $\mathrm{UPR}^{\mathrm{mt}}$ activation can have either beneficial or detrimental effects in the context of neurodegenerative conditions.

\section{$U P R^{m t}$ Signaling in Cancer}

Cancer is a complex and multifactorial disease that is often associated with mitochondrial dysfunction because of the hypoxic environment within tumors, accumulation of mtDNA muta- tions, and relatively high levels of ROS (Chatterjee et al. 2006; Liou and Storz 2010; Boland et al. 2013). Tumor cells rely more heavily on glycolysis rather than OXPHOS despite the presence of oxygen, a phenomenon known as the Warburg effect. Defects in mitochondrial function of cancer cells may contribute to altered flux in metabolic pathways giving rise to the Warburg effect. Accumulating evidence suggests that $\mathrm{UPR}^{\mathrm{mt}}$ activation, in response to mitochondrial dysfunction, contributes to cancer cell growth and survival. For example, expression of Hsp60 is induced in multiple cancer types presumably to maintain mitochondrial function (Cappello et al. 2002; Tsai et al. 2008). Furthermore, activation of ISR kinases PERK, GCN2, and PKR has been implicated in tumor cell survival and neoplastic growth although the mechanistic consequences of mitochondrial dysfunction in tumor cells remain unclear (Kim et al. 2000, 2002; Ye et al. 2010; Nagelkerke et al. 2013). Specifically, in gastric cancers, evidence indicates that ROS activates ATF4 via GCN2 causing enhanced resistance to the chemotherapeutic drug cisplatin (Wang et al. 2016a). Numerous studies have shown a role for ATF5 in the growth of a variety of cancer cell types, suggesting $\mathrm{UPR}^{\mathrm{mt}}$ inhibition may be a viable means to limit cancer progression (Chen et al. 2012; Wang et al. 2012; Nukuda et al. 2016; Angelastro 2017).

\section{$U P R^{m t}$ Signaling during Pathogenic Infection}

Bacterial pathogens secrete a wide array of virulence effectors that curb host functions to establish a persistent infection. Multiple pathogen-secreted virulence factors specifically target host mitochondrial function. For example, the opportunistic pathogen Pseudomonas aeruginosa perturbs mitochondria by secreting toxins, such as cyanide and siderophores, that impair OXPHOS (Kirienko et al. 2015; Managò et al. 2015). Recent studies in C. elegans show that pathogenic and nonpathogenic strains of Pseudomonas perturb mitochondrial function and activate the UPR ${ }^{\mathrm{mt}}$ (Fig. 3) (Liu et al. 2014; Pellegrino et al. 2014). Surprisingly, these studies revealed that in addition to mitochondrial-protective genes, ATFS-1 mediates the induction 
Regulation of the Mitochondrial Unfolded Protein Response

of antibacterial genes, including secreted lysozymes and antimicrobial peptides, as well as xenobiotic detoxification genes (Pellegrino et al. 2014). Importantly, worms lacking ATFS-1 were susceptible to infection, whereas hyperactivation of the UPR ${ }^{\mathrm{mt}}$ limited infection and prolonged host survival. These findings indicate that the UPR ${ }^{\mathrm{mt}}$ functions as an innate immune response and one mechanism by which eukaryotes can detect the presence of bacterial species that produce mitochondrial toxins, including OXPHOS and mitochondrial ribosome inhibitors (tetracyclines), is by monitoring mitochon- drial function via the $\mathrm{UPR}^{\mathrm{mt}}$ (Pellegrino et al. 2014). In turn, the $U_{P R}{ }^{\mathrm{mt}}$ activates a response to maintain mitochondrial function, and rid the host of the pathogen as well as the toxins.

\section{Additional Mechanisms for Mitochondrial Quality Control}

In addition to the UPR ${ }^{\mathrm{mt}}$, several other mechanisms are activated during mitochondrial dysfunction to promote recovery of the mitochondrial network as well as alleviate pleiotropic toxic effects throughout the cell (Fig. 4). Intrigu-
A mPOS

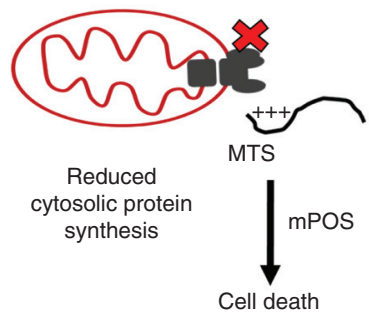

B UPRam

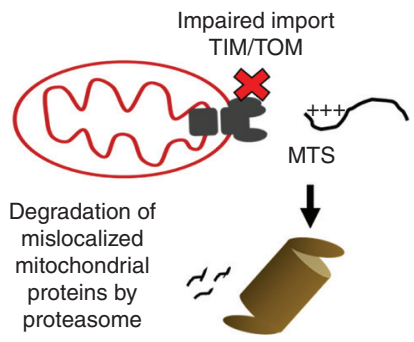

C Mitophagy

Damaged

mitochondria

PINK1 accumulates on OMM

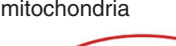
(P)

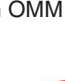

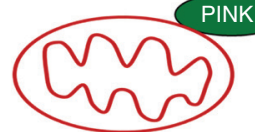
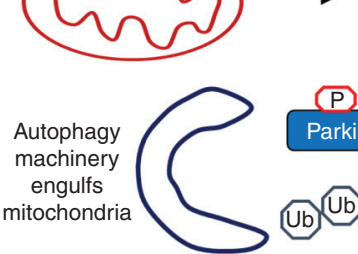

D mitoCPR

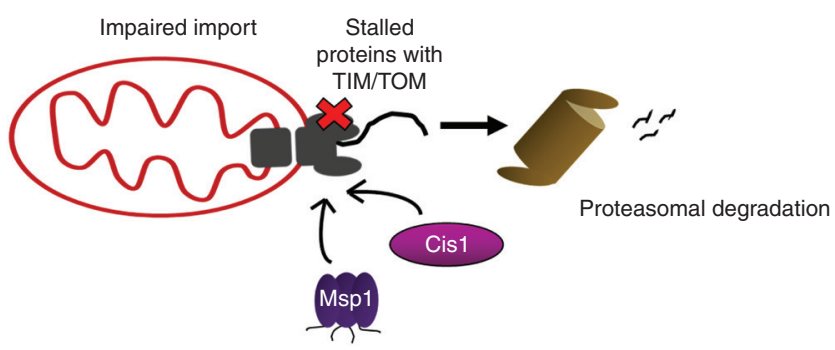

Figure 4. Mitochondrial stress-response pathways that potentially interact with the mitochondrial unfolded protein response $\left(\mathrm{UPR}^{\mathrm{mt}}\right)$. (A) Impaired mitochondrial protein import caused by mitochondrial metabolic or proteostasis defects causes accumulation of mitochondrial precursor proteins in the cytosol and cell death; a pathway termed mPOS (mitochondrial precursor overaccumulation stress). (B) UPRam (unfolded protein response activated by mistargeted proteins) is activated during mitochondrial protein import failure, which causes accumulation of mitochondrial precursor proteins in the cytosol. To rid the cytosol of the toxic mislocalized proteins, proteasomal activity is increased. (C) Mitophagy is a process by which severely damaged mitochondria are degraded. The kinase PINK1 accumulates on the outer membrane of damaged mitochondria (OMM), where it phosphorylates ubiquitin and the E3 ubiquitin ligase Parkin, which leads to polyubiquitination of many OMM proteins. Subsequently, recognition by the autophagy machinery results in engulfment of the defective organelle, which is then delivered to lysosomes for degradation. $(D)$ mitoCPR (mitochondrial compromised protein import response) is a stress-response activated by accumulation or stalling of mitochondrial precursor proteins within TOM (translocase of outer membrane) channels. The linker protein Cis1 is transcriptionally induced to recruit the ATP-dependent translocase Msp1 to the TOM channel to extract the stalled precursor proteins for proteasomal degradation. MTS, Mitochondrial targeting sequence; TIM, translocase of inner membrane. 
ingly, all the mechanisms are stimulated by impaired mitochondrial protein import. Severely or irrecoverably damaged mitochondria are eliminated via mitophagy, which is a form of selective autophagy. Damaged mitochondria are detected by the protein kinase PINK1, which, like ATFS-1, is regulated by mitochondrial import efficiency. PINK1 is imported into healthy organelles in which it is processed and then degraded (Narendra et al. 2010). During mitochondrial stress, if PINK1 fails to be imported across the mitochondrial inner membrane, it accumulates on the outer membrane with the kinase domain facing the cytosol. Here, PINK1 phosphorylates ubiquitin and the ubiquitin ligase, Parkin, which in turn leads to polyubiquitination of multiple mitochondrial outer membrane proteins (Kondapalli et al. 2012; Kane et al. 2014; Kazlauskaite et al. 2014; Koyano et al. 2014; Ordureau et al. 2014). The accumulation of ubiquitinated mitochondrial proteins recruits adaptor proteins, which facilitate cargo recognition by the autophagy machinery (Heo et al. 2015). In the physiological context, mitophagy plays a role in dynamically modulating the levels of deleterious mitochondrial genome in addition to the UPR ${ }^{\mathrm{mt}}$. Mutations in genes encoding both PINK1 and Parkin cause early-onset Parkinson's disease, suggesting that mitophagy plays a prominent role in maintaining the mitochondrial network within dopaminergic neurons (Lucking et al. 2000; Valente et al. 2004).

Because nearly all mitochondrial-localized proteins are encoded on cytosolic ribosomes, impaired mitochondrial import results in the accumulation of mislocalized mitochondrial precursor proteins within the cytosol. If not reduced, the toxic mislocalized proteins cause cell death via a pathway dubbed mPOS (mitochondrial precursor overaccumulation stress) (Wang and Chen 2015). Although the mechanism by which mPOS causes cell death remains to be determined, at least two approaches are used to alleviate toxicity, including increased proteasomal activity to degrade the mislocalized proteins and reduced cytosolic translation to decrease the expression of mitochondrial precursors, which ultimately cannot be imported. These studies emphasize the damaging effects that mitochondrial dysfunction can have on the cytosol, and highlight cellular activities or pathways that serve to restore cytosolic proteostasis, collectively known as UPRam (unfolded protein response activated by mistargeting of proteins) (Wrobel et al. 2015).

Furthermore, a novel pathway that is activated specifically to resolve mitochondrial import stress known as mitoCPR (mitochondrial compromised protein import response) was discovered recently (Weidberg and Amon 2018). mitoCPR induces a transcriptional program that comprises more than 200 genes, including $\mathrm{ABC}$ transporters, and is regulated by a transcription factor PDR3 (pleiotropic drug resistance 3). Intriguingly, PDR3 induces the expression of Cis1, which recruits the ATP-dependent translocase Msp1 (mitochondrial sorting protein) to the TOM channel to facilitate the extraction and degradation of stalled proteins. Thus, mitoCPR functions to alleviate import stress and restore homeostasis by facilitating clearance of stalled precursor proteins.

The existence of multiple quality-control pathways, in addition to the UPR ${ }^{\mathrm{mt}}$, illustrates the difficulty and importance of maintaining mitochondrial proteostasis. For the most part, each of these pathways has been studied in isolation. But, because all are regulated or impacted directly by impaired mitochondrial protein import, it will be exciting to understand how, or if, they interact both temporally and spatially.

\section{PERSPECTIVES}

Over the years, many studies from different organisms have shed light on the pathways that contribute to the maintenance of mitochondrial health and function. We have focused on the $\mathrm{UPR}^{\mathrm{mt}}$, which monitors activity of the mitochondrial network and responds to a wide array of stressors, including proteostasis and metabolic perturbations. Reduced mitochondrial protein import, arising as a consequence of either mitochondrial proteostasis or metabolic stress, leads to nuclear translocation of the transcription factor ATFS-1, which mediates UPR ${ }^{\mathrm{mt}}$ activation, which in turn elicits an adaptive 
transcriptional program. ATFS-1 up-regulates expression of chaperones-encoding genes and promotes mitochondrial biogenesis. UPR ${ }^{\mathrm{mt}}$ activation also modulates protein import and restores mitochondrial proteostasis. This is mechanistically conserved in mammals as the transcription factor ATF5 is also regulated by impaired protein import and organelle partitioning. However, $\mathrm{UPR}^{\mathrm{mt}}$ regulation in mammals requires translation regulation, which necessitates one of four eIF2 $\alpha$ kinases, as well as two additional transcription factors (ATF4 and CHOP), which are intimately associated with the ISR. The ISR has been best characterized as a response to ER stress, but how the pathway is specified to mitochondrial stress is yet to be discovered. It will also be of interest to further understand mechanisms that regulate ATF5 and ATFS-1 mitochondrial protein import efficiency, which may occur by direct protein modifications, such as phosphorylation, or by binding of metabolites and protein partners.

As discussed in this review, the diverse physiological consequences resulting from mitochondrial dysfunction repeatedly underscores the need for further research in understanding the $\mathrm{UPR}^{\mathrm{mt}}$. UPR ${ }^{\mathrm{mt}}$ activation has been shown to have multiple beneficial effects such as promoting mitochondrial recovery, mounting an innate immune response against pathogenic infection, metabolic adaptations, and increasing longevity. However, prolonged $\mathrm{UPR}^{\mathrm{mt}}$ activation can result in neurodegeneration and propagation of deleterious mitochondrial genomes, suggesting that precise regulation of $\mathrm{UPR}^{\mathrm{mt}}$ activation is essential.

\section{ACKNOWLEDGMENTS}

This work was supported by the Howard Hughes Medical Institute (HHMI), the Mallinckrodt Foundation, and National Institutes of Health Grants (R01AG040061 and R01AG0 47182) to C.M.H.

\section{REFERENCES}

Anderson S, Bankier AT, Barrell BG, de Bruijn MH, Coulson AR, Drouin J, Eperon IC, Nierlich DP, Roe BA, Sanger F, et al. 1981. Sequence and organization of the human mitochondrial genome. Nature 290: 457-465. doi:10.1038/ 290457a0

Angelastro JM. 2017. Targeting ATF5 in cancer. Trends Cancer 3: 471-474.

Baker BM, Nargund AM, Sun T, Haynes CM. 2012. Protective coupling of mitochondrial function and protein synthesis via the eIF2 $\alpha$ kinase GCN-2. PLoS Genet 8: e1002760.

Bender T, Lewrenz I, Franken S, Baitzel C, Voos W. 2011. Mitochondrial enzymes are protected from stress-induced aggregation by mitochondrial chaperones and the Pim1/LON protease. Mol Biol Cell 22: 541-554. doi:10.1091/mbc.e10-08-0718

Benedetti C, Haynes CM, Yang Y, Harding HP, Ron D. 2006. Ubiquitin-like protein 5 positively regulates chaperone gene expression in the mitochondrial unfolded protein response. Genetics 174: 229-239.

Berendzen KM, Durieux J, Shao LW, Tian Y, Kim HE, Wolff S, Liu Y, Dillin A. 2016. Neuroendocrine coordination of mitochondrial stress signaling and proteostasis. Cell 166: 1553-1563.e10.

Boland ML, Chourasia AH, Macleod KF. 2013. Mitochondrial dysfunction in cancer. Front Oncol 3: 292. doi: 10.3389/fonc. 2013.00292

Boopathi E, Srinivasan S, Fang JK, Avadhani NG. 2008. Bimodal protein targeting through activation of cryptic mitochondrial targeting signals by an inducible cytosolic endoprotease. Mol Cell 32: 32-42.

Bratic A, Larsson N-G. 2013. The role of mitochondria in aging. J Clin Invest 123: 951-957. doi:10.1172/JCI64125

Cappello F, Bellafiore M, Palma A, Marciano V, Martorana G, Belfiore P, Martorana A, Farina F, Zummo G, Bucchieri F. 2002. Expression of $60-\mathrm{kD}$ heat shock protein increases during carcinogenesis in the uterine exocervix. Pathobiology 70: 83-88. doi:10.1159/000067304

Chacinska A, Koehler CM, Milenkovic D, Lithgow T, Pfanner N. 2009. Importing mitochondrial proteins: Machineries and mechanisms. Cell 138: 628-644.

Chatterjee A, Mambo E, Sidransky D. 2006. Mitochondrial DNA mutations in human cancer. Oncogene 25: 46634674. doi:10.1038/sj.onc.1209604

Chen JJ, London IM. 1995. Regulation of protein synthesis by heme-regulated eIF-2 $\alpha$ kinase. Trends Biochem Sci 20: 105-108. doi:10.1016/S0968-0004(00)88975-6

Chen A, Qian D, Wang B, Hu M, Lu J, Qi Y, Liu DX. 2012. ATF5 is overexpressed in epithelial ovarian carcinomas and interference with its function increases apoptosis through the downregulation of Bcl-2 in SKOV-3 cells. Int J Gynecol Pathol 31: 532-537.

Cheng MY, Hartl FU, Martin J, Pollock RA, Kalousek F, Neuper W, Hallberg EM, Hallberg RL, Horwich AL. 1989. Mitochondrial heat-shock protein hsp60 is essential for assembly of proteins imported into yeast mitochondria. Nature 337: 620-625. doi:10.1038/337620a0

Chung HK, Ryu D, Kim KS, Chang JY, Kim YK, Yi HS, Kang SG, Choi MJ, Lee SE, Jung SB, et al. 2017. Growth differentiation factor 15 is a myomitokine governing systemic energy homeostasis. J Cell Biol 216: 149-165. doi: $10.1083 /$ jcb. 201607110 
Colombo S, Longhi R, Alcaro S, Ortuso F, Sprocati T, Flora A, Borgese N. 2005. $N$-myristoylation determines dual targeting of mammalian NADH-cytochrome b5 reductase to ER and mitochondrial outer membranes by a mechanism of kinetic partitioning. J Cell Biol 168: 735-745.

Copeland JM, Cho J, Lo T Jr, Hur JH, Bahadorani S, Arabyan T, Rabie J, Soh J, Walker DW. 2009. Extension of Drosophila life span by RNAi of the mitochondrial respiratory chain. Curr Biol 19: 1591-1598.

Curtis JM, Hahn WS, Stone MD, Inda JJ, Droullard DJ Kuzmicic JP, Donoghue MA, Long EK, Armien AG, Lavandero S, et al. 2012. Protein carbonylation and adipocyte mitochondrial function. J Biol Chem 287: 3296732980.

Dailey TA, Woodruff JH, Dailey HA. 2005. Examination of mitochondrial protein targeting of haem synthetic enzymes: In vivo identification of three functional haemresponsive motifs in 5-aminolaevulinate synthase. Biochem J 386: 381-386. doi:10.1042/BJ20040570

Deng J, Harding HP, Raught B, Gingras AC, Berlanga JJ, Scheuner D, Kaufman RJ, Ron D, Sonenberg N. 2002. Activation of GCN2 in UV-irradiated cells inhibits translation. Curr Biol 12: 1279-1286. doi:10.1016/S0960-9822 (02)01037-0

Dever TE, Feng L, Wek RC, Cigan AM, Donahue TF, Hinnebusch AG. 1992. Phosphorylation of initiation factor $2 \alpha$ by protein kinase GCN2 mediates gene-specific translational control of GCN4 in yeast. Cell 68: 585-596. doi:10.1016/0092-8674(92)90193-G

Dillin A, Hsu AL, Arantes-Oliveira N, Lehrer-Graiwer J, Hsin H, Fraser AG, Kamath RS, Ahringer J, Kenyon C. 2002. Rates of behavior and aging specified by mitochondrial function during development. Science 298: 23982401. doi:10.1126/science. 1077780

D'Silva PD, Schilke B, Walter W, Andrew A, Craig EA. 2003. $J$ protein cochaperone of the mitochondrial inner membrane required for protein import into the mitochondrial matrix. Proc Natl Acad Sci 100: 13839-13844.

Durieux J, Wolff S, Dillin A. 2011. The cell-non-autonomous nature of electron transport chain-mediated longevity. Cell 144: 79-91.

Feng J, Bussière F, Hekimi S. 2001. Mitochondrial electron transport is a key determinant of life span in Caenorhabditis elegans. Dev Cell 1: 633-644. doi:10.1016/S15345807(01)00071-5

Fiorese CJ, Schulz AM, Lin YF, Rosin N, Pellegrino MW, Haynes CM. 2016. The transcription factor ATF5 mediates a mammalian mitochondrial UPR. Curr Biol 26: 2037-2043.

Gaume B, Klaus C, Ungermann C, Guiard B, Neupert W, Brunner M. 1998. Unfolding of preproteins upon import into mitochondria. EMBO J 17: 6497-6507.

Gerbeth C, Schmidt O, Rao S, Harbauer AB, Mikropoulou D, Opalińska M, Guiard B, Pfanner N, Meisinger C. 2013. Glucose-induced regulation of protein import receptor Tom 22 by cytosolic and mitochondria-bound kinases. Cell Metab 18: 578-587.

Gitschlag BL, Kirby CS, Samuels DC, Gangula RD, Mallal SA, Patel MR. 2016. Homeostatic responses regulate selfish mitochondrial genome dynamics in C. elegans. Cell Metab 24: 91-103.
Gray MW. 2012. Mitochondrial evolution. Cold Spring Harb Perspect Biol. 4: a011403.

Harbauer AB, Zahedi RP, Sickmann A, Pfanner N, Meisinger C. 2014. The protein import machinery of mitochondria-a regulatory hub in metabolism, stress, and disease. Cell Metab 19: 357-372.

Harding HP, Zhang Y, Ron D. 1999. Protein translation and folding are coupled by an endoplasmic-reticulum-resident kinase. Nature 397: 271-274. doi:10.1038/16729

Harding HP, Novoa I, Zhang Y, Zeng H, Wek R, Schapira M, Ron D. 2000. Regulated translation initiation controls stress-induced gene expression in mammalian cells. $\mathrm{Mol}$ Cell 6: 1099-1108. doi:10.1016/S1097-2765(00)00108-8

Hashimoto M, Rockenstein E, Crews L, Masliah E. 2003. Role of protein aggregation in mitochondrial dysfunction and neurodegeneration in Alzheimer's and Parkinson's diseases. Neuromol Med 4: 21-36. doi:10.1385/NMM:4: $1-2: 21$

Haynes CM, Petrova K, Benedetti C, Yang Y, Ron D. 2007. ClpP mediates activation of a mitochondrial unfolded protein response in C. elegans. Dev Cell 13: 467-480.

Haynes CM, Yang Y, Blais SP, Neubert TA, Ron D. 2010. The matrix peptide exporter HAF-1 signals a mitochondrial UPR by activating the transcription factor ZC376.7 in C. elegans. Mol Cell 37: 529-540.

Heo JM, Ordureau A, Paulo JA, Rinehart J, Harper JW. 2015. The PINK1-PARKIN mitochondrial ubiquitylation pathway drives a program of OPTN/NDP52 recruitment and TBK1 activation to promote mitophagy. Mol Cell 60: $7-$ 20.

Hill K, Model K, Ryan MT, Dietmeier K, Martin F, Wagner R, Pfanner N. 1998. Tom40 forms the hydrophilic channel of the mitochondrial import pore for preproteins [see comment]. Nature 395: 516-521. doi:10.1038/26780

Horibe T, Hoogenraad NJ. 2007. The chop gene contains an element for the positive regulation of the mitochondrial unfolded protein response. PLoS ONE 2: e835.

Horst M, Oppliger W, Rospert S, Schönfeld HJ, Schatz G, Azem A. 1997. Sequential action of two hsp70 complexes during protein import into mitochondria. $E M B O J \mathbf{1 6}$ : 1842-1849. doi:10.1093/emboj/16.8.1842

Houtkooper RH, Mouchiroud L, Ryu D, Moullan N, Katsyuba E, Knott G, Williams RW, Auwerx J. 2013. Mitonuclear protein imbalance as a conserved longevity mechanism. Nature 497: 451-457. doi:10.1038/nature12188

Kane LA, Lazarou M, Fogel AI, Li Y, Yamano K, Sarraf SA, Banerjee S, Youle RJ. 2014. PINK1 phosphorylates ubiquitin to activate Parkin E3 ubiquitin ligase activity. J Cell Biol 205: 143-153. doi:10.1083/jcb.201402104

Kazlauskaite A, Kondapalli C, Gourlay R, Campbell DG, Ritorto MS, Hofmann K, Alessi DR, Knebel A, Trost M, Muqit MM. 2014. Parkin is activated by PINK1-dependent phosphorylation of ubiquitin at $\mathrm{Ser}^{65}$. Biochem J460: 127-141. doi:10.1042/BJ20140334

Khan NA, Nikkanen J, Yatsuga S, Jackson C, Wang L, Pradhan S, Kivelä R, Pessia A, Velagapudi V, Suomalainen A. 2017. mTORC1 regulates mitochondrial integrated stress response and mitochondrial myopathy progression. Cell Metab 26: 419-428.e5.

Kim SH, Forman AP, Mathews MB, Gunnery S. 2000. Human breast cancer cells contain elevated levels and activity 
Regulation of the Mitochondrial Unfolded Protein Response

of the protein kinase, PKR. Oncogene 19: 3086-3094. doi:10.1038/sj.onc. 1203632

Kim SH, Gunnery S, Choe JK, Mathews MB. 2002. Neoplastic progression in melanoma and colon cancer is associated with increased expression and activity of the interferon-inducible protein kinase, PKR. Oncogene 21: 8741-8748. doi:10.1038/sj.onc.1205987

Kim KH, Jeong YT, Kim SH, Jung HS, Park KS, Lee HY, Lee MS. 2013a. Metformin-induced inhibition of the mitochondrial respiratory chain increases FGF21 expression via ATF4 activation. Biochem Biophys Res Commun 440: $76-81$.

Kim KH, Jeong YT, Oh H, Kim SH, Cho JM, Kim YN, Kim SS, Kim DH, Hur KY, Kim HK, et al. 2013b. Autophagy deficiency leads to protection from obesity and insulin resistance by inducing Fgf21 as a mitokine. Nat Med 19: 83-92. doi:10.1038/nm.3014

Kirienko NV, Ausubel FM, Ruvkun G. 2015. Mitophagy confers resistance to siderophore-mediated killing by Pseudomonas aeruginosa. Proc Natl Acad Sci 112: 18211826.

Kondapalli C, Kazlauskaite A, Zhang N, Woodroof HI, Campbell DG, Gourlay R, Burchell L, Walden H, Macartney TJ, Deak M, et al. 2012. PINK1 is activated by mitochondrial membrane potential depolarization and stimulates Parkin E3 ligase activity by phosphorylating Serine 65. Open Biol 2: 120080. doi:10.1098/rsob.120080

Koyano F, Okatsu K, Kosako H, Tamura Y, Go E, Kimura M, Kimura Y, Tsuchiya H, Yoshihara H, Hirokawa T, et al. 2014. Ubiquitin is phosphorylated by PINK1 to activate parkin. Nature 510: 162-166. doi:10.1038/nature 13392

Kujoth GC, Hiona A, Pugh TD, Someya S, Panzer K, Wohlgemuth SE, Hofer T, Seo AY, Sullivan R, Jobling WA, et al. 2005. Mitochondrial DNA mutations, oxidative stress, and apoptosis in mammalian aging. Science 309: 481484. doi:10.1126/science.1112125

Leonhard K, Herrmann JM, Stuart RA, Mannhaupt G, Neupert W, Langer T. 1996. AAA proteases with catalytic sites on opposite membrane surfaces comprise a proteolytic system for the ATP-dependent degradation of inner membrane proteins in mitochondria. $E M B O J$ 15: 4218-4229. doi:10.1002/j.1460-2075.1996.tb00796.x

Lin YF, Schulz AM, Pellegrino MW, Lu Y, Shaham S, Haynes CM. 2016. Maintenance and propagation of a deleterious mitochondrial genome by the mitochondrial unfolded protein response. Nature 533: 416-419. doi:10.1038/ nature17989

Liou GY, Storz P. 2010. Reactive oxygen species in cancer. Free Radic Res 44: 479-496.Liu X, Jiang N, Hughes B, Bigras E, Shoubridge E, Hekimi S. 2005. Evolutionary conservation of the clk-1-dependent mechanism of longevity: Loss of mclk1 increases cellular fitness and lifespan in mice. Genes Dev 19: 2424-2434. doi:10.1101/ gad.1352905

Liu Y, Samuel BS, Breen PC, Ruvkun G. 2014. Caenorhabditis elegans pathways that surveil and defend mitochondria. Nature 508: 406-410. doi:10.1038/nature13204

Lucking CB, Durr A, Bonifati V, Vaughan J, De Michele G, Gasser T, Harhangi BS, Meco G, Denefle P, Wood NW, et al. 2000. Association between early-onset Parkinson's disease and mutations in the parkin gene. New Engl J Med 342: $1560-1567$.
Magnuson B, Ekim B, Fingar DC. 2012. Regulation and function of ribosomal protein S6 kinase (S6K) within mTOR signalling networks. Biochem J 441: 1-21. doi: 10.1042/BJ20110892

Managò A, Becker KA, Carpinteiro A, Wilker B, Soddemann M, Seitz AP, Edwards MJ, Grassmé H, Szabò I, Gulbins E. 2015. Pseudomonas aeruginosa pyocyanin induces neutrophil death via mitochondrial reactive oxygen species and mitochondrial acid sphingomyelinase. Antioxid Redox Signal 22: 1097-1110. doi:10.1089/ars.2014.5979

Mapa K, Sikor M, Kudryavtsev V, Waegemann K, Kalinin S, Seidel CA, Neupert W, Lamb DC, Mokranjac D. 2010. The conformational dynamics of the mitochondrial Hsp70 chaperone. Mol Cell 38: 89-100.

Martin J, Mahlke K, Pfanner N. 1991. Role of an energized inner membrane in mitochondrial protein import. $\Delta \Psi$ drives the movement of presequences. J Biol Chem 266: 18051-18057.

Martinez BA, Petersen DA, Gaeta AL, Stanley SP, Caldwell GA, Caldwell KA. 2017. Dysregulation of the mitochondrial unfolded protein response induces non-apoptotic dopaminergic neurodegeneration in C. elegans models of Parkinson's disease. J Neurosci 37: 11085-11100.

Martinus RD, Garth GP, Webster TL, Cartwright P, Naylor DJ, Høj PB, Hoogenraad NJ. 1996. Selective induction of mitochondrial chaperones in response to loss of the mitochondrial genome. Eur J Biochem 240: 98-103. doi:10.1111/j.1432-1033.1996.0098h.x

Mayer A, Nargang FE, Neupert W, Lill R. 1995. MOM22 is a receptor for mitochondrial targeting sequences and cooperates with MOM19. EMBO J 14: 4204-4211. doi: 10.1002/j.1460-2075.1995.tb00094.x

Meisinger C, Ryan MT, Hill K, Model K, Lim JH, Sickmann A, Muller H, Meyer HE, Wagner R, Pfanner N. 2001. Protein import channel of the outer mitochondrial membrane: A highly stable Tom40-Tom 22 core structure differentially interacts with preproteins, small tom proteins, and import receptors. Mol Cell Biol 21: 2337-2348. doi:10.1128/MCB.21.7.2337-2348.2001

Melber A, Haynes CM. 2018. UPR ${ }^{\mathrm{mt}}$ regulation and output: A stress response mediated by mitochondrial-nuclear communication. Cell Res 28: 281-295. doi:10.1038/cr. 2018.16

Merkwirth C, Jovaisaite V, Durieux J, Matilainen O, Jordan SD, Quiros PM, Steffen KK, Williams EG, Mouchiroud L, Tronnes SU, et al. 2016. Two conserved histone demethylases regulate mitochondrial stress-induced longevity. Cell 165: 1209-1223.

Meurs E, Chong K, Galabru J, Thomas NS, Kerr IM, Williams BR, Hovanessian AG. 1990. Molecular cloning and characterization of the human double-stranded RNA-activated protein kinase induced by interferon. Cell 62: 379390. doi:10.1016/0092-8674(90)90374-N

Miller FJ, Rosenfeldt FL, Zhang C, Linnane AW, Nagley P. 2003. Precise determination of mitochondrial DNA copy number in human skeletal and cardiac muscle by a PCRbased assay: Lack of change of copy number with age. Nucleic Acids Res 31: e61. doi:10.1093/nar/gng060

Moehle EA, Shen K, Dillin A. 2018. Mitochondrial proteostasis in the context of cellular and organismal health and aging. J Biol Chem doi:10.1074/jbc.TM117.000893 
Mouchiroud L, Houtkooper RH, Moullan N, Katsyuba E, Ryu D, Canto C, Mottis A, Jo YS, Viswanathan M, Schoonjans K, et al. 2013. The $\mathrm{NAD}^{+} /$sirtuin pathway modulates longevity through activation of mitochondrial UPR and FOXO signaling. Cell 154: 430-441.

Munakata H, Sun JY, Yoshida K, Nakatani T, Honda E, Hayakawa S, Furuyama K, Hayashi N. 2004. Role of the heme regulatory motif in the heme-mediated inhibition of mitochondrial import of 5-aminolevulinate synthase. J Biochem 136: 233-238. doi:10.1093/jb/mvh112

Münch C, Harper JW. 2016. Mitochondrial unfolded protein response controls matrix pre-RNA processing and translation. Nature 534: 710-713. doi:10.1038/nature18302

Nagelkerke A, Bussink J, Mujcic H, Wouters BG, Lehmann S, Sweep FC, Span PN. 2013. Hypoxia stimulates migration of breast cancer cells via the PERK/ATF4/LAMP3arm of the unfolded protein response. Breast Cancer Res 15: R2. doi:10.1186/bcr3373

Narendra DP, Jin SM, Tanaka A, Suen DF, Gautier CA, Shen J, Cookson MR, Youle RJ. 2010. PINK1 is selectively stabilized on impaired mitochondria to activate Parkin. PLoS Biol 8: e1000298.

Nargund AM, Pellegrino MW, Fiorese CJ, Baker BM, Haynes CM. 2012. Mitochondrial import efficiency of ATFS-1 regulates mitochondrial UPR activation. Science 337: 587-590. doi:10.1126/science. 1223560

Nargund AM, Fiorese CJ, Pellegrino MW, Deng P, Haynes CM. 2015. Mitochondrial and nuclear accumulation of the transcription factor ATFS-1 promotes OXPHOS recovery during the UPR ${ }^{\mathrm{mt}}$. Mol Cell 58: 123-133.

Nukuda A, Endoh H, Yasuda M, Mizutani T, Kawabata K, Haga H. 2016. Role of ATF5 in the invasive potential of diverse human cancer cell lines. Biochem Biophys Res Commun 474: 509-514.

Ordureau A, Sarraf SA, Duda DM, Heo JM, Jedrychowski MP, Sviderskiy VO, Olszewski JL, Koerber JT, Xie T, Beausoleil SA, et al. 2014. Quantitative proteomics reveal a feedforward mechanism for mitochondrial PARKIN translocation and ubiquitin chain synthesis. Mol Cell 56: $360-375$.

Owusu-Ansah E, Song W, Perrimon N. 2013. Muscle mitohormesis promotes longevity via systemic repression of insulin signaling. Cell 155: 699-712.

Pathak VK, Schindler D, Hershey JW. 1988. Generation of a mutant form of protein synthesis initiation factor eIF-2 lacking the site of phosphorylation by eIF-2 kinases. $\mathrm{Mol}$ Cell Biol 8: 993-995. doi:10.1128/MCB.8.2.993

Pellegrino MW, Nargund AM, Kirienko NV, Gillis R, Fiorese CJ, Haynes CM. 2014. Mitochondrial UPR-regulated innate immunity provides resistance to pathogen infection. Nature 516: 414-417. doi:10.1038/nature13818

Pfeffer G, Chinnery PF. 2013. Diagnosis and treatment of mitochondrial myopathies. Ann Med 45: 4-16.

Pickles S, Vigié P, Youle RJ. 2018. Mitophagy and quality control mechanisms in mitochondrial maintenance. Curr Biol 28: R170-R185.

Quirós PM, Prado MA, Zamboni N, D’Amico D, Williams RW, Finley D, Gygi SP, Auwerx J. 2017. Multi-omics analysis identifies ATF4 as a key regulator of the mitochondrial stress response in mammals. J Cell Biol 216: 2027-2045. doi:10.1083/jcb.201702058
Rao S, Gerbeth C, Harbauer A, Mikropoulou D, Meisinger C, Schmidt O. 2011. Signaling at the gate: Phosphorylation of the mitochondrial protein import machinery. Cell Cycle 10: 2083-2090. doi:10.4161/cc.10.13.16054

Rao S, Schmidt O, Harbauer AB, Schonfisch B, Guiard B, Pfanner N, Meisinger C. 2012. Biogenesis of the preprotein translocase of the outer mitochondrial membrane: protein kinase A phosphorylates the precursor of Tom40 and impairs its import. Mol Biol Cell 23: 16181627. doi:10.1091/mbc.e11-11-0933

Rauthan M, Ranji P, Aguilera Pradenas N, Pitot C, Pilon M. 2013. The mitochondrial unfolded protein response activator ATFS-1 protects cells from inhibition of the mevalonate pathway. Proc Natl Acad Sci 110: 5981-5986.

Rohde J, Heitman J, Cardenas ME. 2001. The TOR kinases link nutrient sensing to cell growth. J Biol Chem 276: 9583-9586. doi:10.1074/jbc.R000034200

Rossmanith W. 2012. Of P and Z: Mitochondrial tRNA processing enzymes. Biochim Biophys Acta 1819: 1017-1026. Runkel ED, Liu S, Baumeister R, Schulze E. 2013. Surveillance-activated defenses block the ROS-induced mitochondrial unfolded protein response. PLoS Genet 9: e1003346.

Saitoh T, Igura M, Obita T, Ose T, Kojima R, Maenaka K, Endo T, Kohda D. 2007. Tom20 recognizes mitochondrial presequences through dynamic equilibrium among multiple bound states. EMBO J 26: 4777-4787.

Schmidt O, Harbauer AB, Rao S, Eyrich B, Zahedi RP, Stojanovski D, Schonfisch B, Guiard B, Sickmann A, Pfanner $\mathrm{N}$, et al. 2011. Regulation of mitochondrial protein import by cytosolic kinases. Cell 144: 227-239.

Shao LW, Niu R, Liu Y. 2016. Neuropeptide signals cell nonautonomous mitochondrial unfolded protein response. Cell Res 26: 1182-1196. doi:10.1038/cr.2016.118

Shpilka T, Haynes CM. 2018. The mitochondrial UPR: Mechanisms, physiological functions and implications in ageing. Nat Rev Mol Cell Biol 19: 109-120. doi: 10.1038/nrm.2017.110

Silva JM, Wong A, Carelli V, Cortopassi GA. 2009. Inhibition of mitochondrial function induces an integrated stress response in oligodendroglia. Neurobiol Dis 34: 357-365.

Sorrentino V. 2017. Enhancing mitochondrial proteostasis reduces amyloid- $\beta$ proteotoxicity. Nature 552: 187-193.

Stehling O, Lill R. 2013. The role of mitochondria in cellular iron-sulfur protein biogenesis: Mechanisms, connected processes, and diseases. Cold Spring Harb Perspect Biol 5: $\mathrm{a} 011312$.

Strobel G, Zollner A, Angermayr M, Bandlow W. 2002. Competition of spontaneous protein folding and mitochondrial import causes dual subcellular location of major adenylate kinase. Mol Biol Cell 13: 1439-1448. doi:10.1091/mbc.01-08-0396

Suomalainen A. 2015. Mitochondrial roles in disease: A box full of surprises. EMBO Mol Med 7: 1245-1247.

Tatsuta T, Langer T. 2009. AAA proteases in mitochondria: Diverse functions of membrane-bound proteolytic machines. Res Microbiol 160: 711-717.

Teperino R, Schoonjans K, Auwerx J. 2010. Histone methyl transferases and demethylases; Can they link metabolism and transcription? Cell Metab 12: 321-327. 
Tian Y, Garcia G, Bian Q, Steffen KK, Joe L, Wolff S, Meyer BJ, Dillin A. 2016. Mitochondrial stress induces chromatin reorganization to promote longevity and $\mathrm{UPR}^{\mathrm{mt}}$. Cell 165: $1197-1208$

Trifunovic A, Wredenberg A, Falkenberg M, Spelbrink JN Rovio AT, Bruder CE, Bohlooly YM, Gidlof S, Oldfors A, Wibom R, et al. 2004. Premature ageing in mice expressing defective mitochondrial DNA polymerase. Nature 429: 417-423. doi:10.1038/nature02517

Truscott KN, Kovermann P, Geissler A, Merlin A, Meijer M, Driessen AJ, Rassow J, Pfanner N, Wagner R. 2001. A presequence- and voltage-sensitive channel of the mitochondrial preprotein translocase formed by Tim23. Nat Struct Biol 8: 1074-1082. doi:10.1038/nsb726

Tsai YP, Teng SC, Wu KJ. 2008. Direct regulation of HSP60 expression by c-MYC induces transformation. FEBS Lett 582: 4083-4088.

Tsukada Y, Fang J, Erdjument-Bromage H, Warren ME, Borchers $\mathrm{CH}$, Tempst P, Zhang Y. 2006. Histone demethylation by a family of JmjC domain-containing proteins. Nature 439: 811-816. doi:10.1038/nature04433

Tuppen HA, Blakely EL, Turnbull DM, Taylor RW. 2010. Mitochondrial DNA mutations and human disease. Biochim Biophys Acta 1797: 113-128.

Valente EM, Abou-Sleiman PM, Caputo V, Muqit MM, Harvey K, Gispert S, Ali Z, Del Turco D, Bentivoglio AR, Healy DG, et al. 2004. Hereditary early-onset Parkinson's disease caused by mutations in PINK1. Science 304: 1158-1160. doi:10.1126/science.1096284

Vandecasteele G, Szabadkai G, Rizzuto R. 2001. Mitochondrial calcium homeostasis: Mechanisms and molecules. IUBMB Life 52: 213-219.

Voisine C, Craig EA, Zufall N, von Ahsen O, Pfanner N, Voos W. 1999. The protein import motor of mitochondria: Unfolding and trapping of preproteins are distinct and separable functions of matrix Hsp70. Cell 97: 565574. doi:10.1016/S0092-8674(00)80768-0

Vongsamphanh R, Fortier PK, Ramotar D. 2001. Pirlp mediates translocation of the yeast Apn1p endonuclease into the mitochondria to maintain genomic stability. Mol Cell Biol 21: 1647-1655. doi:10.1128/MCB.21.5.1647-1655. 2001

Wang X, Chen XJ. 2015. A cytosolic network suppressing mitochondria-mediated proteostatic stress and cell death Nature 524: 481-484. doi:10.1038/nature 14859

Wang C, Youle RJ. 2009. The role of mitochondria in apoptosis. Annu Rev Genet 43: 95-118. doi:10.1146/annurevgenet-102108-134850
Wang SZ, Ou J, Zhu LJ, Green MR. 2012. Transcription factor ATF5 is required for terminal differentiation and survival of olfactory sensory neurons. Proc Natl Acad Sci 109: 18589-18594.

Wang SF, Chen MS, Chou YC, Ueng YF, Yin PH, Yeh TS, Lee HC. 2016a. Mitochondrial dysfunction enhances cisplatin resistance in human gastric cancer cells via the ROSactivated GCN2-eIF2 $\alpha$-ATF4-xCT pathway. Oncotarget 7: 74132-74151.

Wang X, Pandey AK, Mulligan MK, Williams EG, Mozhui K, Li Z, Jovaisaite V, Quarles LD, Xiao Z, Huang J, et al. 2016b. Joint mouse-human phenome-wide association to test gene function and disease risk. Nat Commun 7: 10464. doi:10.1038/ncomms 10464

Weidberg H, Amon A. 2018. MitoCPR-A surveillance pathway that protects mitochondria in response to protein import stress. Science 360: eaan4146. doi:10.1126/ science.aan4146

Weinberg SE, Sena LA, Chandel NS. 2015. Mitochondria in the regulation of innate and adaptive immunity. Immunity 42: 406-417.

Wrobel L, Topf U, Bragoszewski P, Wiese S, Sztolsztener ME, Oeljeklaus S, Varabyova A, Lirski M, Chroscicki P, Mroczek S, et al. 2015. Mistargeted mitochondrial proteins activate a proteostatic response in the cytosol. Nature 524: 485-488. doi:10.1038/nature14951

Ye J, Kumanova M, Hart LS, Sloane K, Zhang H, De Panis DN, Bobrovnikova-Marjon E, Diehl JA, Ron D, Koumenis C. 2010. The GCN2-ATF4 pathway is critical for tumour cell survival and proliferation in response to nutrient deprivation. EMBO J 29: 2082-2096. doi:10.1038/ emboj.2010.81

Yoneda T, Benedetti C, Urano F, Clark SG, Harding HP, Ron D. 2004. Compartment-specific perturbation of protein handling activates genes encoding mitochondrial chaperones. J Cell Sci 117: 4055-4066. doi:10.1242/jcs. 01275

Zhang Q, Wu X, Chen P, Liu L, Xin N, Tian Y, Dillin A. 2018. The mitochondrial unfolded protein response is mediated cell-non-autonomously by retromer-dependent wnt signaling. Cell 174: 870-883.e17. doi:10.1016/j.cell.2018. 06.029

Zhao Q, Wang J, Levichkin IV, Stasinopoulos S, Ryan MT, Hoogenraad NJ. 2002. A mitochondrial specific stress response in mammalian cells. EMBO J 21: 4411-4419. doi:10.1093/emboj/cdf445 


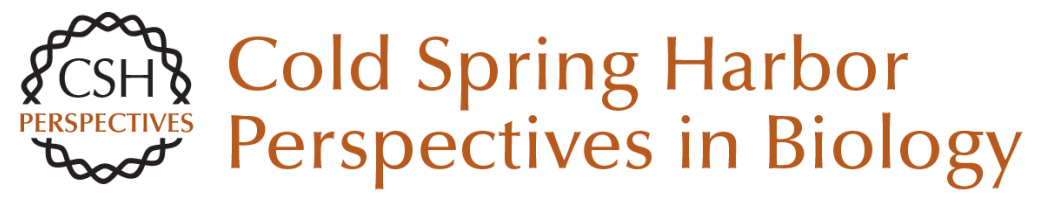

\section{Signaling and Regulation of the Mitochondrial Unfolded Protein Response}

Nandhitha Uma Naresh and Cole M. Haynes

Cold Spring Harb Perspect Biol 2019; doi: 10.1101/cshperspect.a033944 originally published online January 7, 2019

\section{Subject Collection Protein Homeostasis}

Proteome-Scale Mapping of Perturbed

Proteostasis in Living Cells

Isabel Lam, Erinc Hallacli and Vikram Khurana

Pharmacologic Approaches for Adapting

Proteostasis in the Secretory Pathway to

Ameliorate Protein Conformational Diseases Jeffery W. Kelly

Cell-Nonautonomous Regulation of Proteostasis

in Aging and Disease

Richard I. Morimoto

The Autophagy Lysosomal Pathway and

Neurodegeneration

Steven Finkbeiner

Functional Modules of the Proteostasis Network Gopal G. Jayaraj, Mark S. Hipp and F. Ulrich Hartl

Protein Solubility Predictions Using the CamSol

Method in the Study of Protein Homeostasis Pietro Sormanni and Michele Vendruscolo

Recognition and Degradation of Mislocalized

Proteins in Health and Disease

Ramanujan S. Hegde and Eszter Zavodszky

The Nuclear and DNA-Associated Molecular Chaperone Network

Zlata Gvozdenov, Janhavi Kolhe and Brian C. Freeman
The Amyloid Phenomenon and Its Significance in

Biology and Medicine

Christopher M. Dobson, Tuomas P.J. Knowles and Michele Vendruscolo

A Chemical Biology Approach to the Chaperome

in Cancer-HSP90 and Beyond

Tony Taldone, Tai Wang, Anna Rodina, et al.

Proteostasis in Viral Infection: Unfolding the

Complex Virus-Chaperone Interplay

Ranen Aviner and Judith Frydman

The Proteasome and Its Network: Engineering for

Adaptability

Daniel Finley and Miguel A. Prado

Functional Amyloids

Daniel Otzen and Roland Riek

Chaperone Interactions at the Ribosome Elke Deuerling, Martin Gamerdinger and Stefan G. Kreft

Mechanisms of Small Heat Shock Proteins Maria K. Janowska, Hannah E.R. Baughman, Christopher N. Woods, et al.

Structure, Function, and Regulation of the Hsp90 Machinery

Maximilian M. Biebl and Johannes Buchner

For additional articles in this collection, see http://cshperspectives.cshlp.org/cgi/collection/

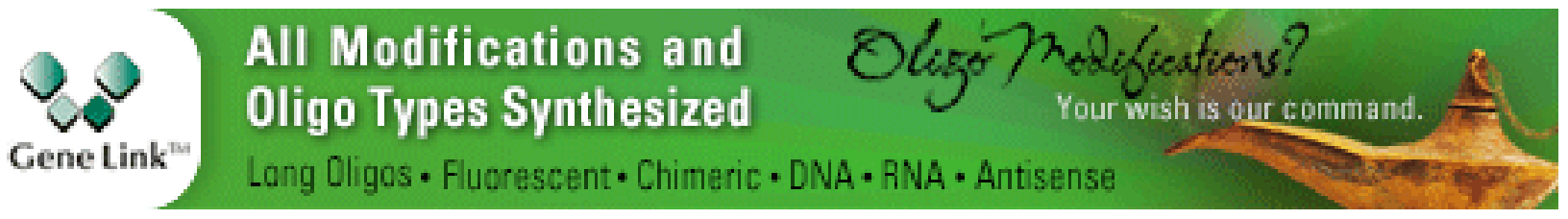


For additional articles in this collection, see http://cshperspectives.cshlp.org/cgi/collection/

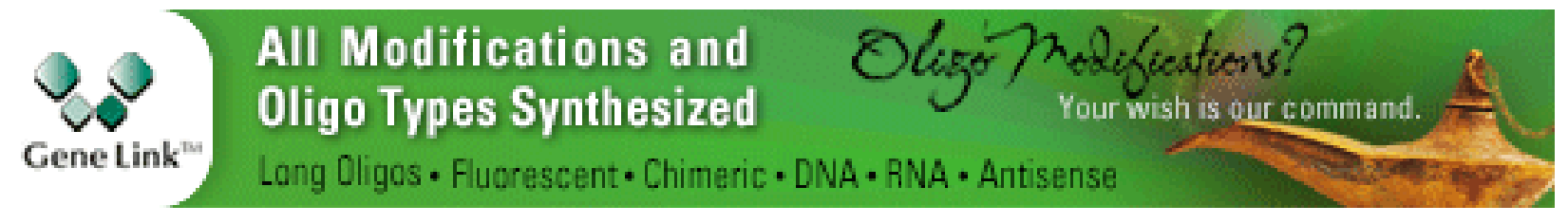

Copyright @ 2019 Cold Spring Harbor Laboratory Press; all rights reserved 